\title{
Does biochemical profile of follicular fluid in women undergoing assisted reproduction vary between the right and left ovaries?
}

\author{
Özkan Özdamar ${ }^{1 *}$, İsmet Gün², Serkan Satılmış Ertuğrul ${ }^{3}$, Okan Özden ${ }^{4}, K_{\text {Kenan Sofuoğlu² }}^{2}$
}

\author{
${ }^{1}$ Department of Obstetrics and Gynecology, Gölcük Military Hospital, Kocaeli, Turkey. \\ ${ }^{2}$ Division of Assisted Reproduction and Endocrinology, Department of Obstetrics and Gynecology, Zeynep Kamil \\ Maternity and Children's Hospital, Istanbul, Turkey. \\ ${ }^{3}$ Department of Obstetrics and Gynecology, Çanakkale Military Hospital, Çanakkale, Turkey. \\ ${ }^{4}$ Department of Obstetrics and Gynecology, GATA Haydarpaşa Training Hospital, İstanbul, Turkey.
}

Received: 24 May 2015

Revised: 07 June 2015

Accepted: 10 July 2015

\section{*Correspondence:}

Dr. Özkan Özdamar,

E-mail: ozkan_ozdamar35@hotmail.com

Copyright: ( $)$ the author(s), publisher and licensee Medip Academy. This is an open-access article distributed under the terms of the Creative Commons Attribution Non-Commercial License, which permits unrestricted non-commercial use, distribution, and reproduction in any medium, provided the original work is properly cited.

\begin{abstract}
Background: Follicular fluid (FF) provides a substantial micro-milieu for the development of the oocytes. Moreover, the content of FF may also reflect the circulating biochemical environment and the changes in blood serum. Despite the known embriyological and histological similarities between right and left ovaries, differences do exist between their venous drainage, anatomical relations and cyclical physiological changes. The difference between the two ovaries in the response to controlled hyperstimulatons $(\mathrm{COH})$ in IVF regimens was later confirmed by recent studies. The aim of this study was to compare the biochemical differences between the FFs yielded from the right and left ovaries in patients undergoing standart IVF treatment.

Methods: A prospective observational study was conducted through the unexplained infertility patients with the age between 23-39 years, body mass index (BMI) $\leq 28 \mathrm{~kg} / \mathrm{m}^{2}, \mathrm{FSH} \leq 10 \mathrm{mIU} / \mathrm{mL}$. FFs aspirated from the right and the left ovary of the patients were assayed for estradiol, calcium, phosphorus, uric acid, urea, total protein, AST, ALT, glucose, sodium, potassium and creatinine. A total of 10 patients undergoing IVF treatments were included.

Results: The investigated parameters were not significantly different between FFs yielded from the right and left ovaries.

Conclusion: According to the results of our study, biochemical profile of the aspirated FFs does not significantly differ between the right and the left ovary and consequently, either right or left ovaries provide similar microenvironments to the developing oocytes.
\end{abstract}

Keywords: Follicular fluid, Infertility, Right ovary, Left ovary, Biochemistry

\section{INTRODUCTION}

Despite recent advances in the field of in vitro fertilization (IVF), success rates remain relatively low, with clinical pregnancy rates still at around $33 \% .^{1}$ All attempts in assisted reproduction to improve pregnancy rates as well as to reduce the possibility of multiple pregnancy are to choose the best quality embryo for transfer and to allow implantation of a single embryo. ${ }^{2}$ Despite the importance of oocyte quality, current assessment of oocytes in assisted reproduction is limited and a variety of methods, including oocyte morphology studies, ${ }^{3}$ molecular and genetic methods ${ }^{4}$ and polar body biopsies $^{5}$ is being employed for oocyte selection. However, most of these techniques are not applicable in the current practice since they are complicated, expensive and time-consuming. ${ }^{6}$

The analysis of follicular fluid has recently been a matter of interest as a possible predictor of both oocyte 
developmental competence and the subsequent potential to achieve fertilization and embryo viability. ${ }^{6-10}$ Moreover, the content of follicular fluid (FF) may also reflect the circulating biochemical environment and the changes in blood serum. ${ }^{11}$

Despite the known embryological and histological similarities between right and left ovaries, differences do exist between their venous drainage, anatomical relations and cyclical physiological changes. Both ovaries receive arterial blood supply directly from the aorta, however, venous drainage differs as the right ovarian vein drains directly to the inferior vena cava (IVC), whereas the left drains firstly to the left renal vein then to the IVC. ${ }^{12}$ On the other hand, intraovarian physiological control of side of ovulation has also been demonstrated to vary between right and the left ovaries, as both fertile and infertile women with two healthy ovaries ovulate significantly more often from the right ovary than the left and ovulation from the right ovary was more likely to achieve pregnancy than the left. ${ }^{13}$ The difference between the two ovaries in the response to controlled hyperstimulatons $(\mathrm{COH})$ in IVF regimens was later confirmed by Lan et al. in 2010. ${ }^{14}$ However, how the superior activity of the right ovary was mediated is poorly understood.

Given that the both ovaries are different in terms of cyclicity and frequency of the ovulation and the ovarian response to $\mathrm{COH}$, it is reasonable to think that the components of FF surrounding the oocyte differ between the right and left ovaries. However, to the best to our knowledge, it has not been investigated whether the biochemical profile of FF vary between the right and left ovaries. Knowing whether, or not, any difference between the FFs yielded from right and left ovaries exist would let us estimate the reproductive destiny of the aspirated oocytes, especially in patients with one ovary or in those in whom the oocyte retrieval procedure is restricted to only one ovary due to anatomical or functional limitations. The objective of this study was to compare the biochemical differences between the FFs yielded from the right and left ovaries in patients undergoing standard IVF treatment.

\section{METHODS}

A prospective observational study was initiated at the Assisted Reproduction and Infertility Department of Zeynep Kamil Training and Educational Hospital, Istanbul, Turkey. Ethical Board approval was obtained prior to the initiation of the study. Patients seeking treatment for solely unexplained infertility were recruited, in a 6 month period between June and December 2013. Inclusion criteria were as follows; age between 23-39 years and body mass index (BMI) $\leq 28 \mathrm{~kg} / \mathrm{m}^{2}$, follicular stimulating hormone (FSH) $\leq 10 \mathrm{mIU} / \mathrm{mL}$, unexplained infertility patients who underwent either agonist or antagonist protocol. Patients with male or tubal factor infertility were excluded.

All patients underwent our standardized IVF treatment protocol. Gonadotropin doses were individualized according to age, BMI, basal hormone levels, antral follicle count (AFC) and previous experiences. Gonadotropin stimulation was achieved by either rFSH or hMG. All patients were administered acetyl-salicilic acid $100 \mathrm{mg}$ daily and folic acid $400 \mathrm{mcg}$ daily simultaneously with the start of the protocol.

Serial ultrasonographic controls and estradiol (E2) level measurements were made until 3 follicles $\geq 17 \mathrm{~mm}$ and a serum E2 level $>500 \mathrm{pg} / \mathrm{ml}$ were detected. Choriogonadotropin alpha $250 \mu \mathrm{g}$ s.c. (Ovitrelle $\AA$; Merck Serono, Italy) was administered to induce final follicular maturation. Transvaginal ultrasound-guided oocyte retrieval was performed 35-36 hours after hCG administration. In both left and right ovary, FFs collected from the first punctured, mature $(>17 \mathrm{~mm})$ follicle at the first entry without contamination, were analyzed; whereas FFs contaminated with blood were not used. All patients were implemented a single dose of cefazolin sodium (Sefazol, Mustafa Nevzat İlaç San., Turkey) $1 \mathrm{gr}$, i.m. at the course of OPU procedure and were given doxycycline $100 \mathrm{mg}$ capsule (Tetradox capsule, Fako Ilaç, Turkey) twice daily and methylprednisolone $16 \mathrm{mg}$ capsule (Prednol tablet, Mustafa Nevzat İlaç San., Turkey) once daily orally and continued for 4 days.

FFs aspirated from the right and the left ovary of the patients were centrifuged for 10 minutes at $2000 \mathrm{xG}$ at room temperature and separated supernatant fluids were assayed for estradiol, calcium, phosphorus, uric acid, urea, total protein, AST, ALT, glucose, sodium, potassium and creatinine. The results of the right and left ovaries were compared. Statistical analyses were performed using the Statistical Package for the Social Sciences for Windows 15.0 software (SPSS, Chicago, IL., USA). Descriptive statistics were given as mean and standard deviation. Non-parametric comparisons were performed using Mann-Whitney U test. Statistical significance was defined as $\mathrm{p}<0.05$.

\section{RESULTS}

A total of 10 patients undergoing IVF treatments were included and the FFs yielded from these patients were compared. According to the results of our study, levels of E2, calcium, sodium, glucose and ALT were higher in the FFs yielded from the left ovary, while phosphorus, urea and total protein were higher in the FFs of the right ovary. However these differences were not statistically different. Meanwhile, potassium, uric acid, creatinine and AST levels were the same between the two ovaries. Consequently, biochemical profile of the aspirated FFs does not significantly differ between the right and the left ovary (Table 1). 
Table 1: Comparison of the biochemical parameters in the FFs yielded from the right and left ovaries.

\begin{tabular}{|llll|}
\hline & Right ovary & Left ovary & p* \\
\hline $\begin{array}{l}\text { Estradiol, } \\
\text { ng/ml }\end{array}$ & $1286.6 \pm 589.1$ & $1440 \pm 743.9$ & 0.796 \\
\hline $\begin{array}{l}\text { Calcium, } \\
\text { mM }\end{array}$ & $7.8 \pm 0.6$ & $7.9 \pm 0.3$ & 0.683 \\
\hline $\begin{array}{l}\text { Phosphorus, } \\
\text { mg/dl }\end{array}$ & $3.4 \pm 0.4$ & $3.3 \pm 0.4$ & 0.791 \\
\hline $\begin{array}{l}\text { Sodium, } \\
\text { mM }\end{array}$ & $139.6 \pm 1.3$ & $140.4 \pm 1.4$ & 0.138 \\
\hline $\begin{array}{l}\text { Potassium, } \\
\text { mM }\end{array}$ & $3.8 \pm 0.8$ & $3.8 \pm 0.8$ & 0.909 \\
\hline AST, IU/l & $28.5 \pm 5.1$ & $28.5 \pm 4.9$ & 0.940 \\
\hline $\begin{array}{l}\text { ALT, IU/l } \\
\text { Glucose, } \\
\text { mg/dl }\end{array}$ & $12.9 \pm 6.0$ & $13.3 \pm 5.1$ & 0.910 \\
\hline $\begin{array}{l}\text { Uric acid, } \\
\text { mg/dl }\end{array}$ & $3.5 \pm 0.6$ & $3.5 \pm 0.5$ & 0.940 \\
\hline $\begin{array}{l}\text { Urea, } \\
\text { mg/dl }\end{array}$ & $23 \pm 5.1$ & $22.8 \pm 4.4$ & 0.999 \\
\hline $\begin{array}{l}\text { Creatinine, } \\
\text { mg/dl }\end{array}$ & $0.8 \pm 0.1$ & $0.8 \pm 0.1$ & 0.912 \\
\hline $\begin{array}{l}\text { Total } \\
\text { protein, } \\
\text { g/dl }\end{array}$ & $5.6 \pm 0.6$ & $5.5 \pm 0.5$ & 0.970 \\
\hline
\end{tabular}

*Mann Whitney-U test.

\section{DISCUSSION}

The right and the left ovaries are not the same regarding venous and lymphatic drainage and regional anatomy, in addition to ovulatory cyclicity. The control of the side of ovulation has been demonstrated in humans firstly in 1987 by Potashnik et al., ${ }^{15}$ who suggested that ovulation tended to occur more frequently in the right ovary. Following studies reported similar results which indicated the difference between the right and left ovaries regarding the frequency of ovulation and the destiny of the ova from the different sides. $^{13,14}$ Lan et al also reported statistically significant differences between the right and left ovarian responses in IVF patients with healthy ovaries and that the right ovarian responses were superior to the left ovarian responses. ${ }^{14}$

The biochemical composition of fluid in mature Graafian follicle is of great importance, since this medium bathes developing oocytes and the composition of FF may have an impact in the oocyte quality, which is a crucial parameter in women undergoing assisted reproduction. FF contains a large variety of metabolites, including hormones, growth factors, interleukins, proteins, peptides and prostanoids that are presumably involved in oocyte growth and development. ${ }^{6}$ The identification and quantification of FF composition can provide valuable information about the oocyte state which can be helpful in distinguishing those oocytes that have a greater capacity to be fertilized and to develop properly. In this context, numerous metabolites have been investigated in recent years. Wallace et al. identified a number of metabolites, including glucose, lactate, choline, phosphocholine, proline, leucine/ isoleucine, glutamine and HDL, as being important indicators of whether a fertilized oocyte will divide and develop into an early cleavage stage embryo or fail to cleave. $^{11}$ Some other studies investigated the composition of free fatty acid and triglyceride in FF in order to clarify whether the levels of lipid content in FF could be predictive to select the best quality oocyte. ${ }^{16-19}$ Peptide and protein composition of FF was analyzed to identify molecules that could be used as markers of good follicular development in order to optimize oocyte selection process. ${ }^{20}$ D'Aniello et al. ${ }^{21}$ demonstrated that D-aspartic acid concentrations in FF correlated with percentage of good morphology, MII oocytes and with the fertilization rate. Józwik et al. ${ }^{22}$ investigated amino acid, ammonia and urea concentrations in FF and reported that their concentrations were higher in FF than in blood. Although differences between the right and left ovaries, regarding the anatomical relations and cyclical physiological changes are well-established, the biochemical profile of FF yielded from the two ovaries has never been compared. In the present, which is a preliminary study in this context, we have investigated the quantitative levels of a total of 12 parameters in the FF, none revealed a statistically significant difference between the FFs from right and left ovaries. Our result might be important in patients with one ovary or in those in whom oocyte pick-up is available only from one ovary due to various limitations. In such cases, we suggest that either right or left ovaries provide similar micro-milieu to the developing oocytes.

One major limitation of this study is that the number of women included in the study is low. However, since the biochemical analysis of the FF is not a routinely applied procedure, we considered to conduct a preliminary study to provide us an opinion on this issue. Further studies in larger cohorts to evaluate the composition of FF are required. In addition, due to the increasing evidence of the relationship between FF metabolite composition and oocyte developmental competence, it is necessary to understand the main influencing factors and how its composition may be modulated to improve oocyte quality.

\section{CONCLUSION}

FFs yielded from the right and left ovaries do not vary in terms of biochemical profile, including estradiol, calcium, phosphorus, uric acid, urea, total protein, AST, ALT, glucose, sodium, potassium and creatinine.

\section{Funding: No funding sources \\ Conflict of interest: None declared}

Ethical approval: The study was approved by the Institutional Ethics Committee 


\section{REFERENCES}

1. Ferraretti AP, Goossens V, Kupka M, Bhattacharya S, de Mouzon J, Castilla JA, et al. European IVFMonitoring (EIM) Consortium for the European Society of Human Reproduction and Embryology (ESHRE). Assisted reproductive technology in Europe, 2009: results generated from European registers by ESHRE. Hum Reprod. 2013;28(9):231831 .

2. Haggarty P, Wood M, Ferguson E, Hoad G, Srikantharajah A, Milne E, et al. Fatty acid metabolism in human preimplantation embryos. Hum Reprod. 2006;21(3):766-73.

3. Balaban B, Urman B. Effect of oocyte morphology on embryo development and implantation. Reprod Biomed Online. 2006;12(5):608-15.

4. Patrizio P, Fragouli E, Bianchi V, Borini A, Wells D. Molecular methods for selection of the ideal oocyte. Reprod Biomed Online. 2007;15:346-53.

5. Dawson A, Griesinger G, Diedrich K. Screening oocytes by polar body biopsy. Reprod Biomed Online. 2006;13(1):104-9.

6. Revelli A, Delle Piane L, Casano S, Molinari E, Massobrio M, Rinaudo P. Follicular fluid content and oocyte quality: from single biochemical markers to metabolomics.Reprod Biol Endocrinol. 2009;7:40.

7. Wu YT, Tang L, Cai J, Lu XE, Xu J, Zhu XM, et al. High bone morphogenic protein-15 level in follicular fluid is associated with high quality oocyte and subsequent embryonic development. Hum Reprod. 2007;22:1526-31.

8. Berker B, Kaya C, Aytac R, Satiroglu H. Homocysteine concentrations in follicular fluid are associated with poor oocyte and embryo qualities in polycystic ovary syndrome patients undergoing assisted reproduction. Hum Reprod. 2009;24(9):2293-302.

9. Piñero-Sagredo E, Nunes S, de los Santos MJ, Celda B, Esteve V. NMR metabolic profile of human follicular fluid. NMR Biomed. 2010;23:485-95.

10. Wallace M, Cottell E, Gibney MJ, McAuliffe FM, Wingfield M, Brennan L. An investigation into the relationship between the metabolic profile of follicular fluid, oocyte developmental potential, and implantation outcome. Fertil Steril. 2012;97:107884.

11. Leroy JL, Vanholder T, Delanghe JR, Opsomer G, Van Soom A, Bols PE, et al. Metabolic changes in follicular fluid of the dominant follicle in highyielding dairy cows early post-partum. Theriogenology 2004;62(6):1131-43.

12. Thomson AJ, Gazvani MR, Wood SJ, Meacock SC, Lewis-Jones DI, Kingsland CR. Comparison of ovarian response in right and left ovaries in IVF patients. Hum Reprod. 2001;16(8):1694-7.
13. Fukuda M, Fukuda K, Andersen CY, Byskov AG. Right-sided ovulation favours pregnancy more than left-sided ovulation. Hum Reprod. 2000;15(9):19216.

14. Lan KC, Huang FJ, Lin YC, Kung FT, Lan TH, Chang SY. Significantly superior response in the right ovary compared with the left ovary after stimulation with follicle-stimulating hormone in a pituitary down-regulation regimen. Fertil Steril. 2010;93(7):2269-73.

15. Potashnik G, Insler V, Meizler I. Frequency, sequence and side of ovulation in women menstruating normally. $\mathrm{Br}$ Med J (Clin Res Ed). 1987;294(6566):219.

16. Jungheim ES, Macones GA, Odem RR, Patterson BW, Lanzendorf SE, Ratts VS, et al. Associations between free fatty acids, cumulus oocyte complex morphology and ovarian function in vitro fertilization. Fertil Steril. 2011;95(6):1970-4.

17. Robker RL, Akison LK, Bennett BD, Thrupp PN, Chura LR, Russell DL, et al. Obese women exhibit differences in ovarian metabolites, hormones and gene expression compared to moderate weight women. J Clin Endocrinol Metab. 2009; 94:1533-40.

18. Yang X, Wu LL, Chura LR, Liang X, Lane M, Norman RJ, et al. Exposure to lipid-rich follicular fluid is associated with endoplasmic reticulum stress and impaired oocyte maturation in cumulus-oocyte complexes. Fertil Steril. 2012;97(6):1438-43.

19. O'Gorman A, Wallace M, Cottell E, Gibney MJ, McAuliffe FM, Wingfield M, et al. Metabolic profiling of human follicular fluid identifies potential biomarkers of oocyte developmental competence. Reproduction. 2013;146(4):389-95.

20. Schweigert FJ, Gericke B, Wolfram W, Kaisers U, Dudenhausen JW. Peptide and protein profiles in serum and follicular fluid of women undergoing IVF. Hum Reprod. 2006;21:2960-8.

21. D'Aniello G, Grieco N, Di Filippo MA, Cappiello F, Topo E, D'Aniello E, et al. Reproductive implication of D-aspartic acid in human pre-ovulatory follicular fluid. Hum Reprod. 2007;22:3178-83.

22. Józwik M, Józwik M, Teng C, Battaglia FC. Amino acid, ammonia and urea concentrations in human pre-ovulatory ovarian follicular fluid. Hum Reprod. 2006;21(11):2776-82.

Cite this article as: Özdamar Ö, Gün İ, Ertuğrul SS, Özden O, Sofuoğlu K. Does biochemical profile of follicular fluid in women undergoing assisted reproduction vary between the right and left ovaries? Int J Reprod Contracept Obstet Gynecol 2015;4:1066-9. 